\title{
Separate roles for the DNA damage checkpoint protein kinases in stabilizing DNA replication forks
}

\author{
Monica Segurado and John F.X. Diffley ${ }^{1}$ \\ Cancer Research UK London Research Institute, Clare Hall Laboratories, South Mimms EN6 3LD, United Kingdom
}

\begin{abstract}
The DNA damage checkpoint plays a crucial role in maintaining functional DNA replication forks when cells are exposed to genotoxic agents. In budding yeast, the protein kinases Mec1 (ATR) and Rad53 (Chk2) are especially important in this process. How these kinases act to stabilize DNA replication forks is currently unknown but is likely to have important implications for understanding how genomic instability is generated during oncogenesis and how chemotherapies that interfere with DNA replication could be improved. Here we show that the sensitivity of rad53 mutants to DNA-damaging agents can be almost completely suppressed by deletion of the EXO1 gene, which encodes an enigmatic flap endonuclease. Deletion of EXO1 also suppresses DNA replication fork instability in rad53 mutants. Surprisingly, deletion of EXO1 is completely ineffective in suppressing both the sensitivity and replication fork breakdown in mec1 mutants, indicating that Mec1 has a genetically separable role in replication fork stabilization from Rad53. Finally, our analysis indicates that a second downstream effector kinase, Chk1, can stabilize replication forks in the absence of Rad53. These results reveal previously unappreciated complexity in the downstream targets of the checkpoint kinases and provide a framework for elucidating the mechanisms of DNA replication fork stabilization by these kinases.
\end{abstract}

[Keywords: Checkpoints; Exo1; Rad53; Mec1; Chk1; DNA replication fork stabilization.]

Supplemental material is available at http://www.genesdev.org.

Received February 26, 2008; revised version accepted April 28, 2008.

Eukaryotic cells require specialized surveillance mechanisms called checkpoints to preserve both viability and genome integrity when confronted with endogenous or exogenous agents that interfere with DNA replication. The loss of checkpoint pathways can lead to genomic instability and thereby promote carcinogenesis (Hartwell and Kastan 1994; Kolodner et al. 2002; Nyberg et al. 2002). The DNA damage checkpoint involves a protein kinase cascade and, in Saccharomyces cerevisiae, the central checkpoint protein kinases are the ATR homolog Mec1 and its downstream effector, the Chk2 homolog Rad53 (Zhou and Elledge 2000). A second effector kinase, Chk1, has a major role in metazoan checkpoints but a fairly minor role in budding yeast checkpoints. In response to S-phase perturbations, Mec1 is recruited to stalled DNA replication forks, where it is required to phosphorylate and activate Rad53 (Branzei and Foiani 2006). When activated, checkpoint pathways regulate many aspects of cell metabolism including cell cycle progression, activation of DNA repair pathways, transcription of DNA damage response genes, DNA replica-

${ }^{1}$ Corresponding author.

E-MAIL John.Diffley@cancer.org.uk; FAX 44-1707-625803.

Article is online at http://www.genesdev.org/cgi/doi/10.1101/gad.477208. tion fork stabilization, and DNA replication origin firing (Santocanale and Diffley 1998; Shirahige et al. 1998; Foiani et al. 2000; Lowndes and Murguia 2000; Tercero and Diffley 2001; Nyberg et al. 2002; Andreassen et al. 2006; Branzei and Foiani 2006).

The role of DNA damage checkpoints in replication fork stabilization appears to be especially important. When DNA replication forks in wild-type cells stall because of deoxynucleoside triphosphate (dNTP) depletion with hydroxyurea (HU), they remain competent to resume replication after removal of $\mathrm{HU}$; however, replication forks are unable to resume replication in rad53 mutants after HU removal (Desany et al. 1998; Lopes et al. 2001; Tercero et al. 2003). Similarly, replication forks in rad53 or mec1 mutants arrest irreversibly during replication through alkylated DNA leading to incomplete replication and cell death (Tercero and Diffley 2001; Tercero et al. 2003). This lethality requires passage through $\mathrm{S}$ phase but is not prevented by blocking subsequent mitotic entry, indicating that the lethal event is associated with DNA replication and that the role of checkpoints in restraining mitosis cannot account for the lethality (Tercero and Diffley 2001). Blocking protein synthesis during $S$ phase in wild-type cells does not render them sensitive to $\mathrm{HU}$, nor does it prevent replication fork resumption 
after HU arrest, arguing that checkpoint-dependent induction of transcription is not critical for fork stabilization or viability (Tercero et al. 2003). A hypomorphic mec1 mutant (mec1-100) that cannot block late origin firing in HU but can stabilize replication forks is much less HU-sensitive than mec1s cells, arguing that regulation of late origin firing plays a relatively minor role in maintaining cell viability (Tercero et al. 2003). Thus, a process of elimination has pointed to DNA replication fork stabilization as the critical role of Rad53 and Mec1 for cell viability after DNA damage.

How checkpoints regulate replication forks is currently unclear. Chromatin immunoprecipitation (ChIP) experiments have suggested that replisomes remain at stalled forks in wild-type cells but are depleted from stalled forks in checkpoint mutant cells /Cobb et al. 2003; Lucca et al. 2004). Long patches of single-strand DNA accumulate at stalled forks in checkpoint mutants probably because of DNA degradation (Sogo et al. 2002; Feng et al. 2006), consistent with catastrophic breakdown of replisome function. Although there are correlations between replisome stability and checkpoint function, the molecular mechanisms by which checkpoints preserve replication fork function and viability remain to be determined.

The roles of the individual protein kinases in regulating DNA replication forks are still unclear. Because Mec1 is essential for Rad53 activation (Branzei and Foiani 2006) and mec1 and rad53 mutants share similar phenotypes (Lopes et al. 2001; Tercero et al. 2003), it is possible that Rad53 is the main effector at stalled forks and the primary role of Mecl in fork stabilization is to activate Rad53. However, Mec1 may have roles at repli- cation forks independent of Rad53. mec1-null mutants are considerably more sensitive and have higher rates of replication fork breakdown than rad53-null mutants in HU or MMS (Gardner et al. 1999; Tercero and Diffley 2001). Moreover, ChIP experiments have indicated that mec1 mutants have defects in replisome stability not seen in rad53 mutants (Bjergbaek et al. 2005; Cobb et al. 2005), although other studies have suggested that rad53 mutants are also defective in replisome stabilization (Lopes et al. 2001; Sogo et al. 2002; Cotta-Ramusino et al. 2005).

In this study, we describe a genetic approach to examine the role of checkpoints at stalled replication forks. Our work demonstrates that Mec1 and Rad53 have genetically separable roles in fork stabilization. The primary role of Rad53 is to prevent Exol-dependent replication fork breakdown. Moreover, we describe experiments indicating a previously unappreciated role for Chk1 in fork stabilization during the intra-S checkpoint.

\section{Results}

Exo1 suppresses the sensitivity of rad53s cells to genotoxic agents

Because of its critical downstream function in the checkpoint pathway, we initially focused on the role of Rad53 in DNA replication fork stabilization. We considered three different models for how the stability of replication forks might be regulated by activated Rad53 (Fig. 1A), any or all of which might be involved in preventing fork collapse and cell death. Firstly, Rad53 might regulate fork stabilization by direct phosphorylation of some
A

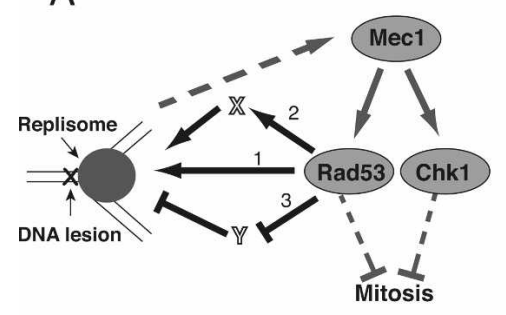

C

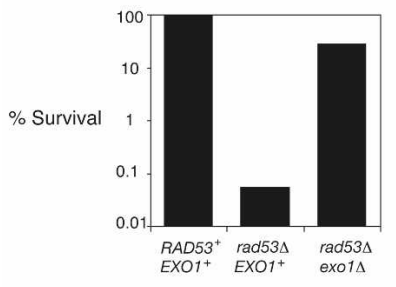

B

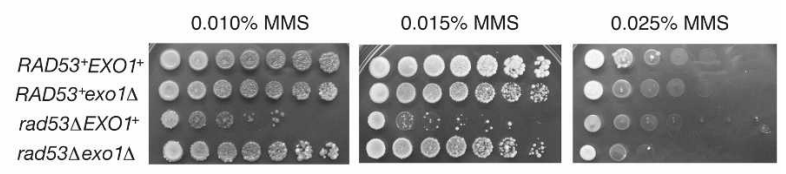

D
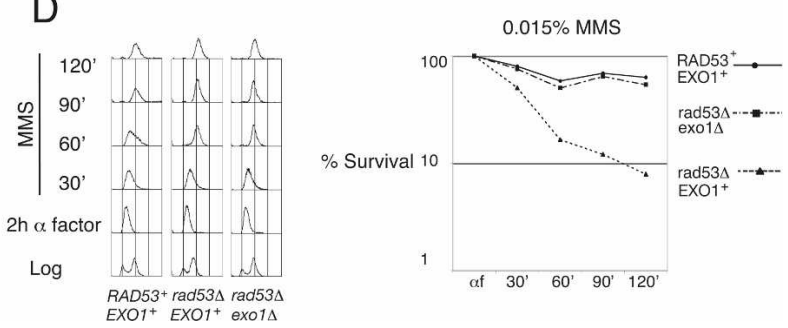

Figure 1. EXO1 is a suppressor of rad53 lethality in MMS. (A) Models for how Rad53 might stabilize stalled replication forks. See the text for details. $(B)$ Drop assays on YPD $+0.010 \%, 0.015 \%$, or $0.025 \%$ MMS were performed using 1:5 serial dilutions of exponentially growing cultures of the indicated strains. $(C)$ Cell viability was measured as colony outgrowth from exponentially growing cultures on YPD + $0.015 \%$ MMS plates. $(D)$ The indicated strains were released from G1 arrest at $30^{\circ} \mathrm{C}$ in YPD medium containing $0.015 \%$ MMS, and samples were taken every $30 \mathrm{~min}$. (Left panel) DNA content was measured by flow cytometry. (Right panel) Cell viability for the three strains used in $C$ was scored during $\alpha$-factor arrest and at the indicated time points during $S$ phase in YPD in the presence of $0.015 \%$ MMS. 
replisome component. To address this, we are currently surveying the replisome for Rad53-dependent phosphorylation, which will be described elsewhere. Secondly, Rad53 might positively regulate some activity $(\mathrm{X})$ that promotes fork stabilization, either by maintaining the replisome at stalled/damaged forks, reloading replisome components for replication restart, or promoting some replication-coupled DNA repair process. In this scenario, overproduction of " $\mathrm{X}$ " might be expected to suppress the sensitivity of rad53 mutants to genotoxic agents. However, we have thus far been unsuccessful in identifying efficient high-copy suppressors of rad53. And thirdly, activated Rad53 might inhibit some activity $(\mathrm{Y})$ that contributes to irreversible fork collapse. In this study, we explore this third option. We reasoned that if the sensitivity of rad53 mutants to DNA replication stress was due, at least in part, to an inability to protect stalled/ damaged forks from "Y," then mutations inactivating " $\mathrm{Y}$ " should increase the viability of rad53 mutant cells in the presence of genotoxic agents. We used Saccharomyces cerevisiae to search for mutations that confer upon rad53 $\Delta$ cells increased resistance to various forms of DNA replication stress. Details of this screen will be published elsewhere; however, one suppressor mutant stood out from all others. We found that deletion of the EXO1 gene very significantly suppressed lethality of rad53-null mutants treated with the DNA alkylating agent methyl methanesulphonate (MMS).

To characterize this suppression, we examined the effect of MMS on wild-type and rad53 $\Delta$ mutant strains in the presence or absence of EXO1 using a serial dilution assay (Fig. 1B). Wild-type cells grew in the presence of $0.010 \%$ and $0.015 \%$ MMS, whereas rad53 4 mutants were extremely sensitive. Above 0.015\% MMS, even wild-type cells were extremely slow growing (Fig. 1B). Deletion of EXO1 alone conferred mild sensitivity to MMS. Strikingly, deletion of EXO1 in the rad53-null background almost completely suppressed its sensitivity to MMS.

We quantified the ability of these strains to form colonies during chronic exposure to MMS. We plated a fixed number of cells of each strain on plates containing $0.015 \%$ MMS and counted surviving colonies, plotted in Figure $1 \mathrm{C}$, as percent survival. Under these conditions, viability of the rad53 $\mathrm{EXO1^{+ }}$ strain was $<0.1 \%$ compared with the $R A D 53^{+} E X O 1^{+}$strain. In contrast, viabil-

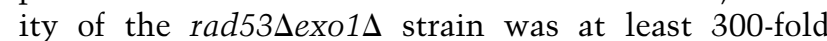
higher than the rad53 $\triangle E X O 1^{+}$strain and only threefold lower than the $R A D 53^{+} E X O 1^{+}$strain. Supplemental Figure 1 shows that deletion of EXO1 also suppressed the MMS sensitivity of strains containing a hypomorphic allele of RAD53 (sad1) (Allen et al. 1994), indicating that suppression is not specific to the RAD53 deletion and does not require deletion of $S M L 1$.

Previously, we showed that rad53s mutants lose viability during passage through a single $S$ phase in the presence of MMS (Tercero and Diffley 2001). To examine the effect of EXO1 deletion on viability in a single cell cycle, cells were synchronized in G1 phase with $\alpha$-factor mating pheromone and released from the G1 arrest in the presence of $0.015 \%$ MMS. DNA replication was examined by flow cytometry (Fig. 1D). As described previously (Paulovich and Hartwell 1995), S phase was rather slow in $R A D 53^{+}$cells but was considerably faster in rad53s cells. This experiment shows that $S$ phase is

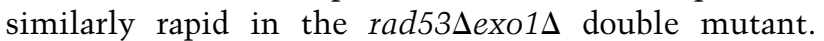
However, Figure 1D (right panel) shows that the rad53s cells lose viability rapidly upon passage through $S$ phase

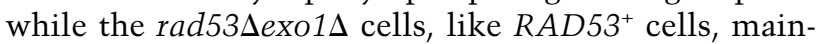
tain high viability. Thus, deletion of EXO1 suppresses most of the loss of viability of rad53 $\Delta$ cells but does not suppress the accelerated $S$ phase. Previous work has attributed the accelerated S phase to an inability of rad53s cells to inhibit late origin firing after DNA damage (Tercero and Diffley 2001). The results described here suggest that deletion of EXO1 in the rad53D background does not restore the block to late origin firing.

We next asked whether deletion of EXO1 could sup-

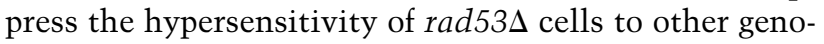
toxic agents including ultraviolet radiation (UV), ionizing radiation (IR), and hydroxyurea (HU). Figure 2 shows that the rad53 $\Delta$ strain was more sensitive than the $R A D 53^{+}$strain to all of the agents tested. After treat-

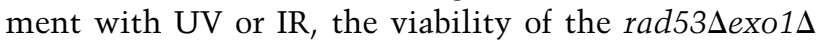
strain was considerably higher than the rad53 $\triangle E X O 1^{+}$ strain, almost as high as the $R A D 53^{+}$strain (Fig. 2). Therefore, the sensitivity of rad53 $\Delta$ cells to a wide range of DNA-damaging agents requires the presence of EXO1. In contrast to the DNA-damaging agents, deletion of EXO1 did not result in a significant increase in the viability of rad53 $\Delta$ cells treated with HU.

Exo1 is a relatively large protein (702-amino-acid residues) with a nuclease domain found in the N-terminal one-third of the protein. To test if the Exol-dependent lethality in rad53 $\Delta$ cells can be attributed to the nuclease activity of Exo1, we constructed strains expressing either wild-type EXO1 or one of two nuclease-deficient versions of EXO1 with mutations in the essential residues D173 and E150, respectively (Fig. 3A). It has been previously shown that changing either of these two resi-

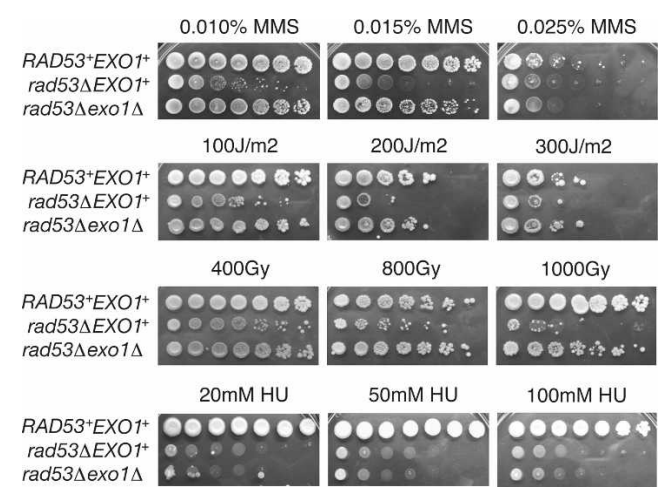

Figure 2. EXO1-dependent suppression occurs in MMS, UV, and IR, but not in HU. Serial dilutions (1:5) of exponential cul-

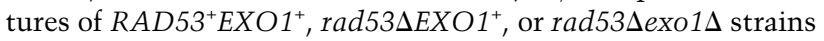
were tested for sensitivity to increasing dosages of MMS, UV, IR, or HU (panels from top to bottom), by using a drop assay on plates. 
A

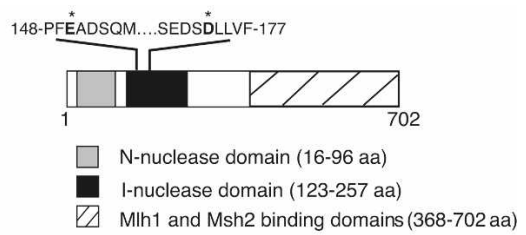

B
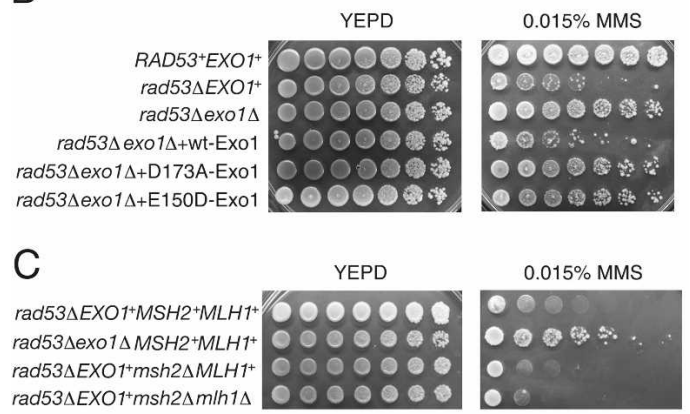

D

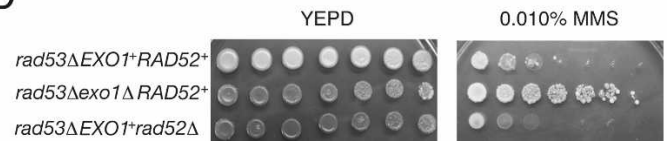

Figure 3. EXO1-dependent lethality is linked to its nuclease activity. (A) Schematic of $S$. cerevisiae Exol with functional nuclease domains and Mlh1/Msh2-binding domains are indicated by gray, black, and striped boxes, respectively. Asterisks highlight the highly conserved Asp 173 or Glu 150 residues within the I-nuclease domain. $(B)$ Nuclease-deficient Exol prevents lethality in rad53 mutants in MMS. Either wild-type or mutated Exol versions were integrated in the genome of a

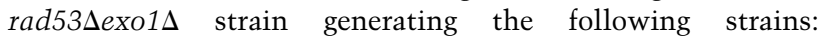

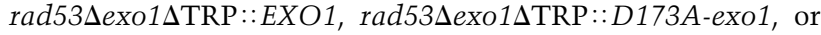

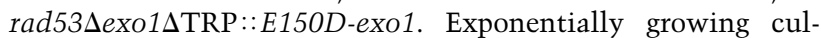
tures of the indicated strains were serially diluted (1:5), and $4 \mu \mathrm{L}$ of each dilution was spotted out onto YPD and YPD + 0.015\%

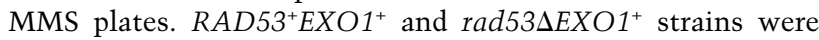
also included as controls. $(C)$ Exol-dependent lethality does not depend on interaction with Msh2 and Mlh1. The indicated strains were grown exponentially, serially diluted (1:5), and spotted onto YPD + 0.015\% MMS. (D) Exol-dependent lethality is not mediated by homologous recombination. The indicated strains were grown exponentially, serially diluted (1:5), and spotted onto YPD + 0.010\% MMS.

dues to alanine dramatically reduces nuclease activity of the protein (Tran et al. 2002). In each case, expression was driven by the EXO1 promoter at the TRP 1 locus in

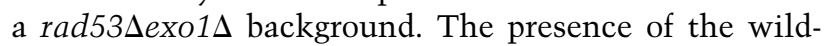
type EXO1 gene reversed the MMS resistance of the strain to rad53 mutant levels, whereas the strains carrying the nuclease-deficient $E X O 1$ copy remained resistant to MMS, like the EXO1 deletion (Fig. 3B). These results indicate that the Exo1-dependent lethality observed in rad53 mutants requires its nuclease activity. Exol has previously been shown to have a positive role in both mismatch repair and homologous recombination. Figure 3C shows that deletion of $M S H 2$, a critical mismatch repair factor, either alone or together with deletion of another mismatch repair factor, $M L H 1$, did not suppress the sensitivity of rad53 $\Delta$ cells to MMS. Figure 3D shows that deletion of $R A D 52$, a critical DNA recombination factor, was also completely ineffective in suppressing the sensitivity of rad53 $\Delta$ cells to MMS. Therefore, the suppression of the hypersensitivity of rad53 $\Delta$ cells to genotoxic agents is not due to the loss of mismatch repair or recombination.

\section{Rescue of replication fork breakdown by EXO1 deletion}

We showed previously that DNA replication forks in both $R A D 53^{+}$and rad53A cells proceed very slowly when cells replicate in the presence of MMS (Tercero and Diffley 2001). Whereas wild-type cells ultimately complete DNA replication, rad53s were unable to finish. This inability to complete DNA replication is correlated with the S-phase-specific loss of viability (Tercero and Diffley 2001; Tercero et al. 2003). Given the strong correlation between loss of viability and inability to complete DNA replication, we were interested in determining whether deletion of EXO1 would allow rad53 $\Delta$ cells to complete DNA replication in MMS.

To investigate this, we used density transfer substitution experiments to quantify replication fork progression (Reynolds et al. 1989; Tercero et al. 2000; Tercero and Diffley 2001). Briefly, cells were grown for at least seven generations in the presence of ${ }^{13} \mathrm{C}$ glucose and ${ }^{15} \mathrm{~N}$ ammonium sulfate, ensuring that both parental DNA strands were fully substituted with heavy isotopes (heavy-heavy; HH). After synchronization in G1 with $\alpha$ factor mating pheromone, cells were allowed to pass through S phase in the presence of MMS and light isotopes $\left({ }^{12} \mathrm{C}\right.$ glucose, ${ }^{14} \mathrm{~N}$ ammonium sulfate), which results in the generation of Heavy-Light (HL) DNA. As shown by flow cytometry in Figure 4A, wild-type cells proceeded slowly through $S$ phase in the presence of MMS, whereas rad530 cells proceeded much faster. As indicated above, EXO1 deletion did not detectably alter the replication kinetics of the rad53 mutant.

DNA preparations from the indicated time points were digested with the appropriate restriction enzyme, and HH-DNA and HL-DNA were separated based on their different density in $\mathrm{CsCl}$ gradients. Replication of each fragment is seen as transfer of DNA from the Heavy-Heavy peak (Fig. 4B-D, HH, gray) to the HeavyLight peak (Fig. 4B-D, HL, unfilled). The position and amounts of DNA in each peak were determined by DNA slot blot hybridization. We used a strain we previously described lacking the origins ARS608 and ARS609, which allows us to track DNA replication across a large 70-kb replicon, between ARS607 and the right end of chromosome VI (Friedman et al. 1997; Yamashita et al. 1997). Figure 4B and Supplemental Figure 2 show DNA replication fork progression in $\mathrm{RAD} 53^{+} \mathrm{EXO} 1^{+}$cells and in $R A D 53^{+}$exo $1 \Delta$ cells, respectively. These patterns are virtually identical to each other and to our previous work. Before replication, each fragment of DNA was present at the position of the fully substituted HH-DNA 


\begin{abstract}
Figure 4. EXO1 deletion rescues replication fork breakdown in rad53 mutants. (A) The indicated strains were arrested in G1 with mating pheromone in the presence of heavy isotopes and released into medium containing light isotopes in the presence of $0.033 \%$ MMS. DNA content was determined by flow cytometry at the indicated time points. $(B)$ Replication fork progression in a wild-type strain $\left(R A D 53^{+} E X O 1^{+}\right)$. DNA replication of a 70-kb region at the end of chromosome VI was followed by density transfer. The position of the six ClaI/SalI restriction fragments analyzed is shown at the top, coinciding with ARS607 and 10, 20, 40, 50, and $65 \mathrm{~kb}$ away from the origin. The position of unreplicated heavy-heavy $(\mathrm{HH})$ and fully replicated heavy-light (HL) DNA peaks is indicated at the bottom. The position of the initial HH peak is shown at all stages by comparison (gray area). The time points indicated correspond to those analyzed by flow cytometry in $A$. The replication pattern in an $R A D 53^{+}$exo1D strain showed no difference from that seen in the $R A D 53^{+} E X O 1^{+}$ strain (see Supplemental Fig. 2). (C) Replication fork progression in a rad53 $E X O 1^{+}$strain. Replication in this checkpoint-deficient strain in MMS was followed exactly as in $B .(D)$ Replication fork progression in a

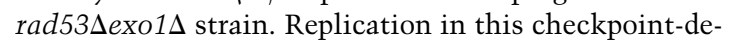
ficient strain in MMS was followed exactly as in $B$. The strains used in $B-D$ harbor deletions of $S M L 1$ to allow viability in the absence of $R A D 53$. (E) Replication fork breakdown rates. The percentage of unreplicated DNA at the end of the experiment was determined as described in the Materials and Methods and was com-

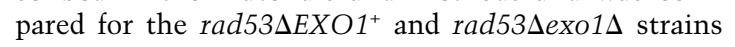
(240 $\mathrm{min}$ in $C$ and $D$ ). The percentage of unreplicated DNA at each fragment was plotted against distance from the ARS607 sequence. Black bars represent the rad53 $\triangle E X O 1^{+}$strain and gray bars represent the

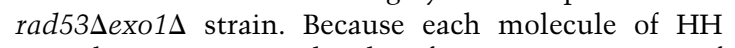
DNA becomes two molecules of HL DNA, amounts of unreplicated and replicated DNA are not directly proportional to peak heights/areas in $A-D$ (see the Materials and Methods).
\end{abstract}

(top row). Replication from ARS607 had already begun by $30 \mathrm{~min}$ after release from G1 arrest. DNA replication in this experiment can be seen to proceed from left to right across the entire replicon because of the sequential transfer of fragments from $\mathrm{HH}$ to HL from left to right along the replicon with time. As previously noted, the origin associated with the $\mathrm{X}$ element at the end of the chromosome (Chan and Tye 1983) appears to remain inactive because the entire replicon is primarily replicated from left to right. Replication was very slow, but by 240 min, the entire region was completely replicated in almost all cells, as previously shown for a checkpoint-proficient strain in the presence of MMS (Tercero and Diffley 2001). There were no significant differences in replication fork progression between $R A D 53^{+} E X O 1^{+}$cells and $R A D 53^{+}$exo1 $\Delta$ cells (Supplemental Fig. 2).

In rad53 $\Delta$ mutants (Fig. $4 \mathrm{C}$ ), the beginning of $S$ phase looked very similar to the pattern shown in Figure 4B.
A
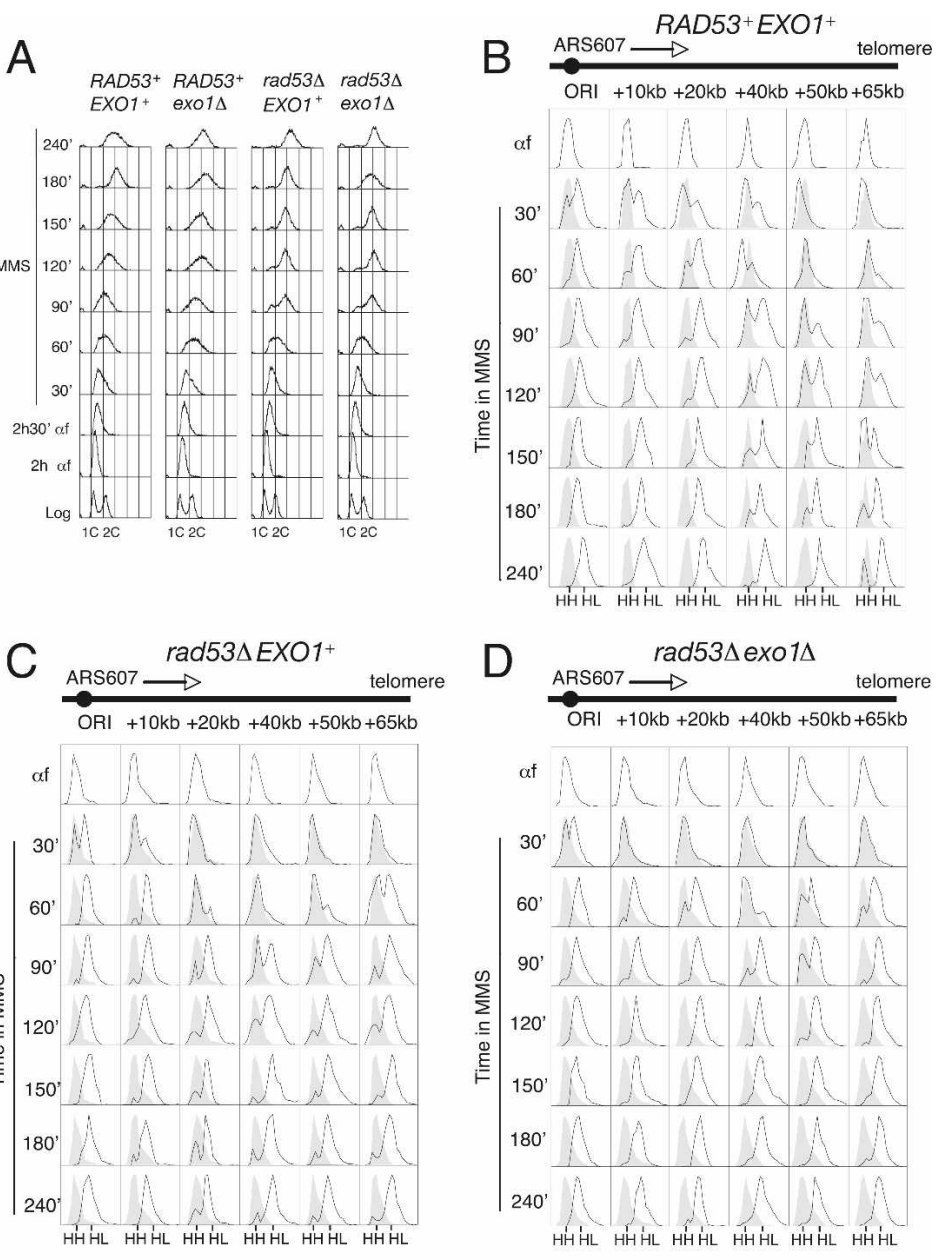

E

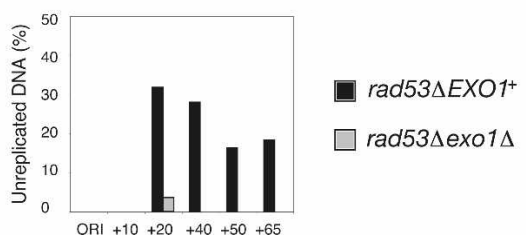

Activation of ARS607 occurred during the first $30 \mathrm{~min}$, and forks proceeded slowly into the adjacent fragments. By $60 \mathrm{~min}$, however, replication forks had also originated from the vicinity of the chromosome end and proceeded from right to left. This can be seen as replication of the +65 - $\mathrm{kb}$ fragment before the +50 - $\mathrm{kb}$ fragment and is essentially identical to our previous experiments, consistent with the loss of Rad53-dependent inhibition of late origin firing after DNA damage. Most importantly, as we previously showed, replication forks arrest irreversibly in this mutant. There is no further DNA synthesis detectable after 120-150 min, although significant amounts of DNA persist in the HH peak for the remainder of the experiment, especially in the origin-distal fragments at $+20 \mathrm{~kb}$ and $+40 \mathrm{~kb}$. We call this "terminally unreplicated DNA."

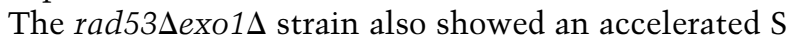
phase, apparently due to inappropriate initiation events 
near the terminus of the chromosome similar to the rad53 $\triangle \mathrm{EXO1}^{+}$strain. However, in contrast to the

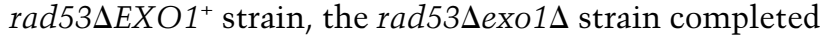
DNA replication as efficiently as a checkpoint proficient strain as shown by the complete transfer of DNA from the $\mathrm{HH}$ to the HL peak (Fig. 4D). Figure 4E shows a quantification of this terminally unreplicated DNA at various positions along the replicon in the rad53 $\triangle E X O 1^{+}$

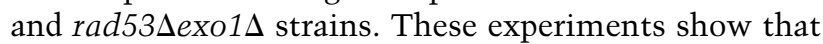
the deletion of EXO1 prevents the irreversible arrest of DNA replication forks in rad53s cells treated with MMS.

rad53 mutant cells are unable to restart stalled DNA replication forks following transient arrest in HU (Paulovich and Hartwell 1995; Desany et al. 1998; Lopes et al. 2001). It has also been shown that Exol specifically affects the stability of replication forks in rad53 mutant cells in HU (Cotta-Ramusino et al. 2005). However, as shown in Figure 2, EXO1 deletion does not rescue the sensitivity of rad53 $\Delta$ cells to HU. Thus, we wondered whether deletion of EXO1 would allow replication forks to restart following HU removal.

To examine this, we analyzed replication resumption after HU arrest by measuring DNA content using flow cytometry. The indicated strains were blocked in G1 with $\alpha$-factor and released into medium containing 0.2 $\mathrm{M} \mathrm{HU}$. After $2 \mathrm{~h}$, cells were transferred to medium lacking $\mathrm{HU}$ but containing nocodazole to prevent passage through mitosis. As shown in Figure 5A, $R A D 53^{+} E X O 1^{+}$ cells completed replication $40 \mathrm{~min}$ after release form $\mathrm{HU}$, whereas rad53 $\triangle E X O 1^{+}$cells were unable to resume significant amounts of DNA synthesis even after $90 \mathrm{~min}$.

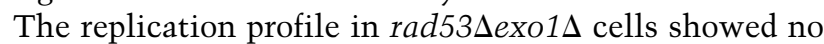

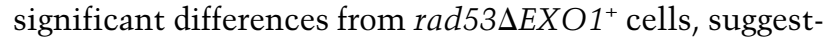
ing that both strains are unable to restart DNA replication from stalled forks after HU treatment.

We next used bromodeoxyuridine (BrdU) pulse-chase experiments to label nascent strands during replication in $\mathrm{HU}$, which allowed us to follow the fate of stalled/ damaged replication forks after HU removal in a more

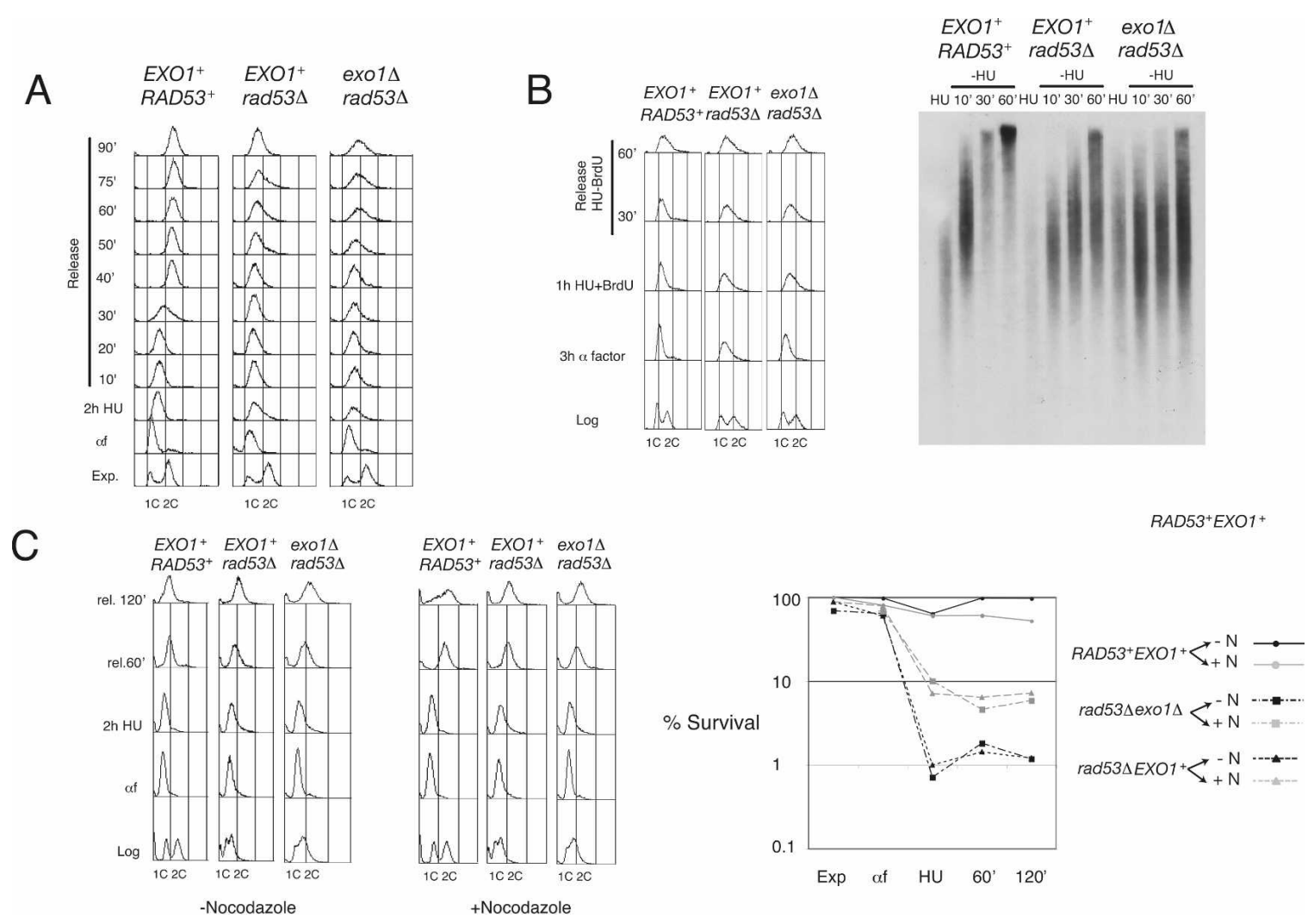

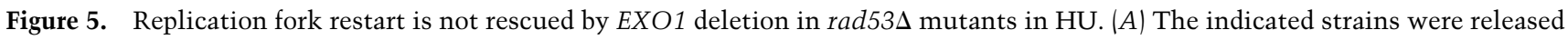
from G1 arrest at $30^{\circ} \mathrm{C}$ in YPD medium containing $0.2 \mathrm{M} \mathrm{HU}$ for $2 \mathrm{~h}$. After that, the cultures were released into fresh medium, and samples were taken every $10 \mathrm{~min}$. DNA content was measured by flow cytometry. $(B)$ Immunodetection of BrdU-pulsed DNA. Cells expressing HSV-TK and hENT1 were arrested in G1 with $\alpha$-factor and released into YPGal in the presence of $0.2 \mathrm{M} \mathrm{HU}+25 \mu \mathrm{M}$ BrdU. After a 1-h pulse with BrdU, 10-min, 30-min, and 60-min samples were taken after release into fresh medium with 2 mM Thy. The DNA content during the time course was measured by flow cytometry. BrdU-labeled DNA was purified and run on a $0.8 \%$ alkaline agarose gel and transferred onto a nylon membrane, before detection with an anti-BrdU antibody. (C) Nocodazole does not prevent

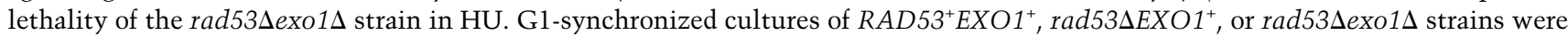
divided in two, and one-half was released into YPD + 0.2 M HU for $2 \mathrm{~h}$ in the presence of nocodazole and then released from HU in the presence of nocodazole. The other half was treated in the same way but in the absence of nocodazole. DNA content and cell viability were analyzed during the course of the experiment at the indicated times. 
direct way. We used strains previously developed in our laboratory that can incorporate BrdU into DNA when present at low concentrations in the medium. These strains express both a nucleoside transporter (hENT) and a thymidine kinase from Herpes Simplex virus (HSV TK) (Vernis et al. 2003), allowing us to perform "pulse-chase" experiments. Cells were synchronized in G1 with $\alpha$-factor and released into medium containing HU and BrdU. After labeling the nascent DNA associated with the stalled forks, the BrdU was chased by transferring cells to fresh medium lacking $\mathrm{HU}$ and BrdU and containing a high concentration of thymidine. DNA was purified, separated on a denaturing alkaline agarose gel, and transferred to a nylon membrane, and the newly replicated DNA was detected with an anti-BrdU antibody as described previously (Vernis et al. 2003).

Nascent DNA replication intermediates labeled in all of the strains at $25^{\circ} \mathrm{C}$ appeared as a smear (Fig. 5B), consistent with similar experiments in which nascent DNA was detected by blot hybridization using origin-specific probes (Santocanale and Diffley 1998). After release, the size of the fragments in $\mathrm{RAD53^{+ }} \mathrm{EXO1}^{+}$cells increased very quickly, and by $60 \mathrm{~min}$ almost all the incorporated BrdU had been chased into the high-molecular-weight fraction, indicating rapid restarting of stalled replication forks. In contrast, in rad53 $\triangle E X O 1^{+}$cells, the majority of the nascent DNA remained at the same position after release, indicating a gross failure of replication forks to resume DNA replication. This pattern was indistinguish-

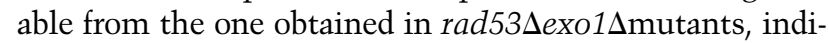

cating that the inability of rad53 $\Delta$ cells to restart fork progression is not rescued by EXO1 deletion.

We wanted to determine if inappropriate entry into mitosis in HU caused by checkpoint loss compromises the suppressor effect of EXO1 deletion. To this end, we measured survival rates in $R A D 53^{+} E X O 1^{+}$, rad53 $\triangle E X O 1^{+}$, and rad53 $\Delta$ exo $1 \Delta$ strains during $H U$ treatment and after release, in the presence or absence of nocodazole (Fig. $5 \mathrm{C})$. There was a very slight increase in viability in both rad53 $\Delta \mathrm{EXO}^{+}$and $\mathrm{rad} 53 \mathrm{\Delta exo} 1 \Delta$ strains in the presence of nocodazole (from $3 \%$ to $6 \%$ ), suggesting that in checkpoint mutants a very small proportion of cells in the population may die because of premature entry into mitosis. However, viability remains below $10 \%$ in both mutant strains, indicating that blocking entry into mitosis is not sufficient to prevent lethality in rad53sexo1s cells in HU or after HU removal.

\section{EXO1 deletion does not rescue a mec1s mutant}

As described in the introduction, the role of Mecl in DNA replication fork stabilization is presently unclear. Mec1 may only be required because of its role in Rad53 activation or it may have an additional, separate role. We reasoned that if the only function of Mec1 is to activate Rad53, EXO1 deletion should also suppress the sensitivity of mec1 mutants to genotoxic stress.

We therefore compared sensitivity of mec1 $1 \Delta X O 1^{+}$

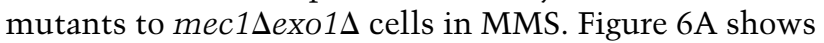
that mec1s cells are considerably more sensitive to
A
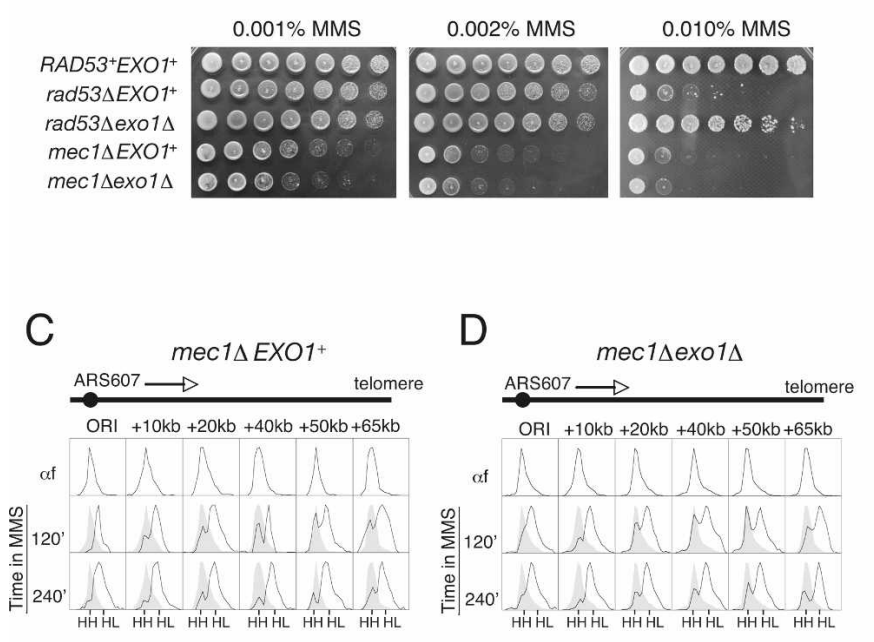

B

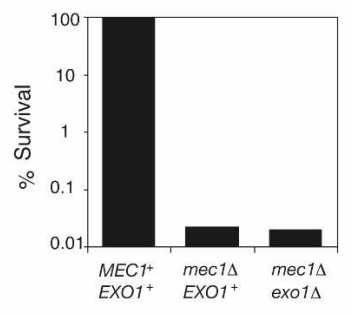

E

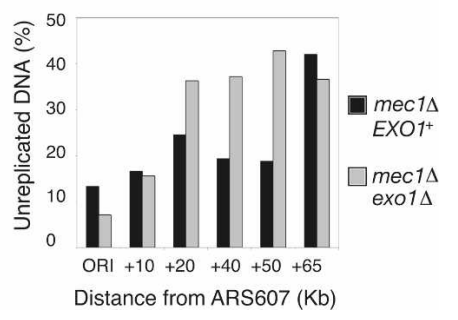

Figure 6. EXO1 deletion does not rescue viability or replication fork breakdown in mec1 mutants. $(A)$ The specified strains were grown exponentially, serially diluted (1:5), and spotted onto YPD plates containing either 0.001\%, 0.002\%, or 0.010\% MMS. (B) An equal number of cells for each strain were plated for viability onto YPD + $0.008 \%$ MMS plates, and numbers of colonies were scored

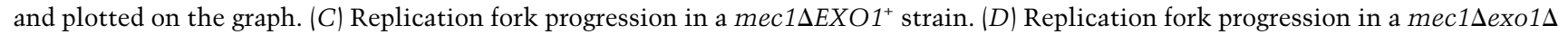

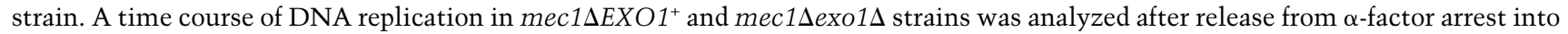
medium with $0.033 \%$ MMS (Supplemental Fig. 3A). Time points corresponding to $120 \mathrm{~min}$ and 240 min after release from G1 block were analyzed by dense-isotope transfer, as described in Figure 4. The strains used in $C$ and $D$ harbor deletions of $S M L 1$ to allow viability in the absence of MEC1. (E) Replication fork breakdown rates. The graph shows the percentage of unreplicated DNA

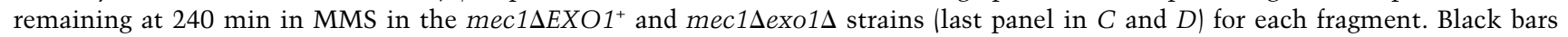

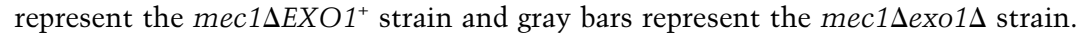


MMS than rad53s cells (note the lower concentrations of MMS). Strikingly, deletion of EXO1 did not increase the viability of the mec1s cells either by serial dilution (Fig. 6A) or in a quantitative survival assay (Fig. 6B).

Next, we investigated replication fork breakdown in mec1sexo1s mutants. We performed density transfer substitution experiments as before. Figure 6, C and D, shows replication fork progression in $m e c 1 \Delta E X O 1^{+}$and mec1 1 exo1 $\Delta$ cells. Both strains showed apparent deregulated activation of the subtelomeric origin, as with the rad53 $\Delta$ cells, evidenced by the premature appearance of HL DNA in the telomere-proximal fragment $+65 \mathrm{~kb}$. Most importantly, however, both strains had a significant proportion of unreplicated, HH DNA even after 240 min (quantified in Fig. 6E), indicating that, in contrast to rad53 mutants, deletion of EXO1 is not sufficient to prevent replication fork breakdown in mec1s cells.

\section{A role for Chk1 in fork stabilization}

We next decided to examine the other downstream effector kinase in the Mec1 pathway, Chk1. Figure 7A shows that chk1s cells are no more sensitive to MMS than $\mathrm{CHK}^{+}$cells, consistent with the idea that Chk1 has a relatively minor role in budding yeast checkpoints. This figure also shows that deletion of EXO1 by itself confers mild sensitivity to MMS and the chk1Dexo1s double mutant is approximately as sensitive to MMS as the $C H K 1^{+}$exo1s cells. We next tested the effect of de- leting CHK1 in a rad53 $\Delta$ background. Figure $7 \mathrm{~B}$ shows that the rad53 $\Delta \operatorname{chk} 1 \Delta$ strain is no more sensitive to MMS than the rad53 $\Delta$ strain and not nearly as sensitive as the mec1s strain. This again suggests that Chk1 has little or no role in the intra-S checkpoint. Strikingly, however, Figure 7B shows that deletion of EXO1 is completely unable to rescue the sensitivity of the rad53 $\Delta \mathrm{chk} 1 \Delta$

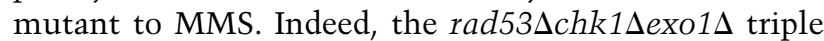
mutant is significantly more MMS-sensitive than the rad $53 \Delta \operatorname{chk} 1 \Delta$ mutant.

Figure 7, C-E, shows that rad53 $\Delta$ chk $1 \Delta$ mutants have very similar levels of irreversible fork breakdown to rad53 $\triangle \mathrm{CHK} 1^{+}$cells (Fig. 4). However, deletion of EXO1

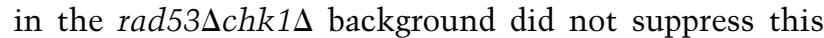
breakdown. Thus, Chk1 is required for the ability of the EXO1 deletion to suppress the lethality and breakdown of replication forks in rad53 5 cells treated with MMS.

Previous work has indicated that the primary function of Chk1 in S. cerevisiae is to stabilize Pds1 and prevent entry into anaphase (Yamamoto et al. 1996; Sanchez et al. 1999; Liu et al. 2000). To ascertain whether preventing entry into mitosis is important to preserve fork integrity in the absence of $R A D 53$, we asked whether the

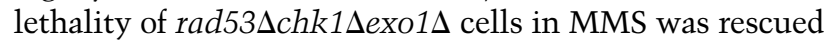

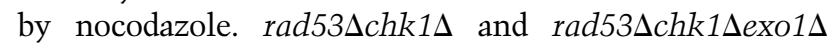
strains were arrested in $\mathrm{G}_{1}$ with mating pheromone and released into $S$ phase in MMS in the presence or absence of nocodazole. Supplemental Figure 4 shows that the presence of nocodazole had little or no effect in protect-
A
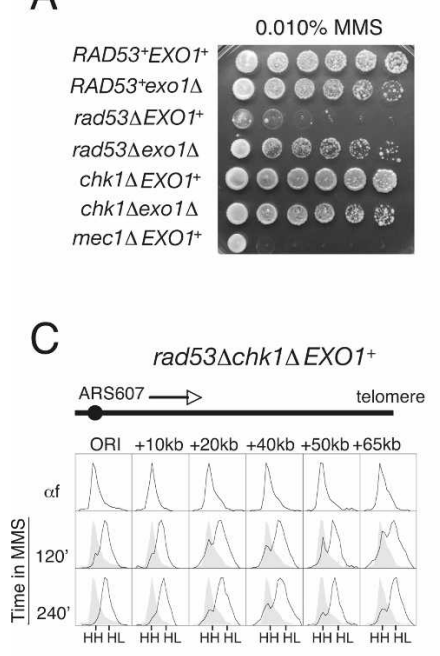

B

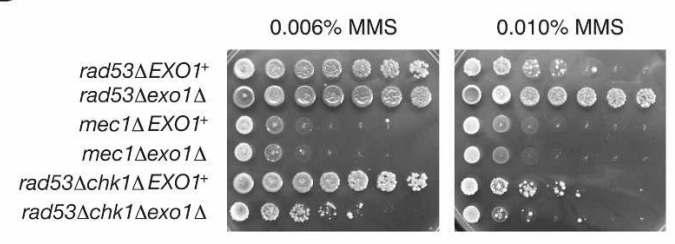

$\mathrm{E}$

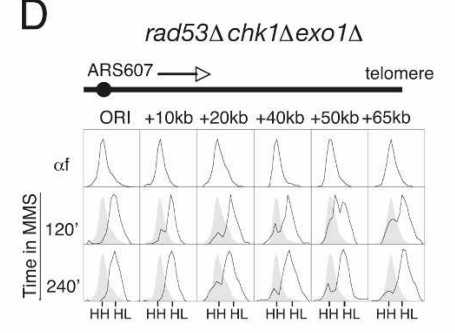

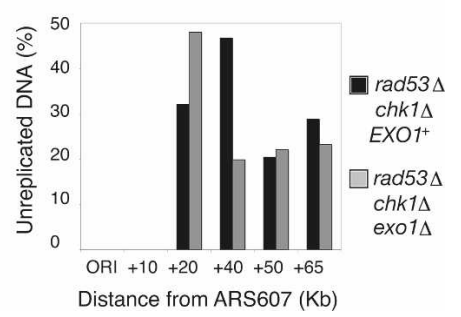

Figure 7. EXO1 deletion does not rescue viability or replication fork breakdown in rad53chk1 mutants. $(A)$ The viability of the indicated strains in YPD $+0.010 \%$ MMS was measured, by performing a drop assay with a 1:5 serial dilution series of exponential

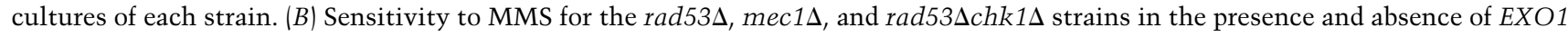
was compared. The indicated strains were grown exponentially, serially diluted (1:5), and spotted onto YPD plates containing either

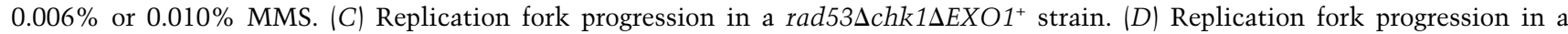

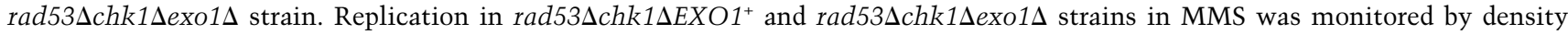
transfer exactly as in Figure 6, C and D. DNA content of the indicated time points is shown in Supplemental Figure 3B. The strains used in $C$ and $D$ harbor deletions of $S M L 1$ to allow viability in the absence of RAD53. (E) Replication fork breakdown rates. The amount of unreplicated DNA remaining at the end of the experiment shown above (last panel in $B$ and $C$ ) was plotted for each fragment

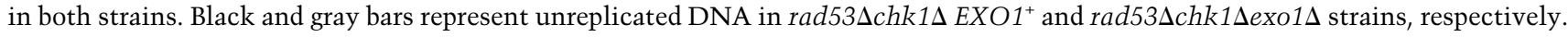


ing either strain from cell lethality. Moreover, with or

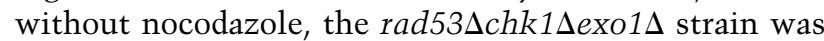

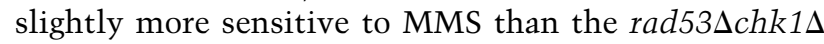
strain. Taken together, these results suggest that Chk1 has a role in maintaining functional DNA replication forks, at least in the absence of Rad53, independent of its role in restraining mitosis.

\section{Discussion}

We argued previously that the most important function of Rad53 in promoting cell survival after DNA damage is to preserve the integrity of DNA replication forks (Tercero and Diffley 2001; Tercero et al. 2003). In this study, we provide additional support for this idea, and we show that the nuclease Exol plays a critical, antagonistic role in this process. Our results also revealed Rad53-independent roles for the Mec1 and Chk1 checkpoint kinases in DNA replication fork stabilization, leading us to suggest that the simple model in Figure 8A is incomplete. Instead, we propose the model shown in Figure 8B.

We show here that the loss of DNA replication fork stability in rad53 $\Delta$ mutants treated with DNA-damaging agents requires Exol and that removal of Exol is sufficient to allow near wild-type levels of fork stabilization in the absence of Rad53. Previous work from Foiani and colleagues has shown that the collapse of DNA replication forks in HU-treated cells requires Exol (Cotta-Ramusino et al. 2005). They showed using 2D gels that replication bubbles degenerate into abnormal structures in HU-treated rad53 mutant cells and that this pheno-
A

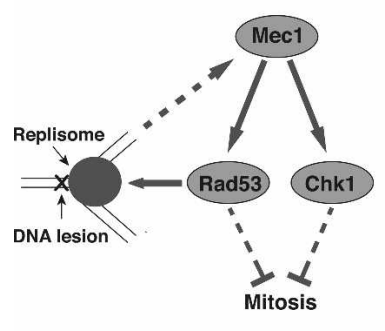

B

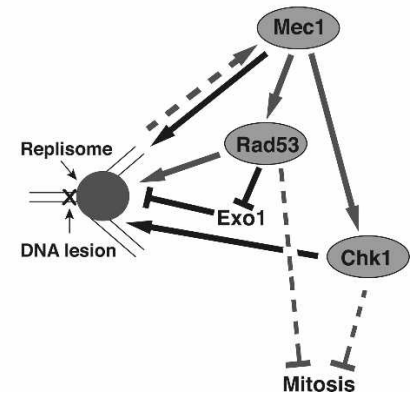

Figure 8. Mec1/Rad53/Chk1 are important to maintain fork integrity. $(A)$ This model summarizes the current view of checkpoint-dependent fork stabilization. The replication forks activate Mec1, the sensor kinase, which then phosphorylates the downstream effector Rad53 kinase. Rad53 acts on the replication forks and stabilize them, whereas the main role of Chk 1 is to prevent entry into mitosis. Rad53 has been also proposed to contribute to inhibition of mitosis. $(B)$ This model summarizes the different pathways implicated in the stability of the replication forks based on our results. Mec1, Rad53, and Chk1 kinases all contribute to fork stabilization. Rad53 works through inhibition of Exol and also has additional roles at the replication forks. Mec1 has a Rad53-independent role at the replication forks, and Chk1 is also involved in fork stabilization in the absence of Rad53. Rad53 and Chk1 both contribute to inhibition of mitosis. Black lines and arrows indicated the additional pathways compared with the model represented in $A$. type is dependent on Exo1. However, they noted that the absence of Exol did not increase the viability of rad53 mutants. Our results are consistent with this; we also observed that EXO1 deletion does not suppress rad53 lethality in HU, nor did it promote replication restart. We suggest that Rad53 stabilizes DNA replication forks via an Exol-dependent and an Exol-independent pathway, both of which are required to maintain functional replication forks in HU. The Exol-independent pathway is not simply Rad53-dependent restraint of mitotic entry

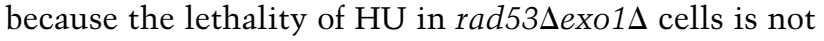
suppressed by nocodazole. Our results show that, in MMS, UV, and IR, Rad53 works primarily via the Exo1dependent pathway. Previous work has shown that the hypersensitivity of rad53 mutants to MMS is almost entirely due to problems during DNA replication. The results presented here suggest that at least some of the hypersensitivity of rad53 mutants to IR and UV may also be due to difficulties during DNA replication.

We presently do not know the mechanism by which Exol interferes with the integrity of the replication forks. It may be that Rad53 controls the stability of some replisome component at the fork. Loss of this component in the absence of Rad53 would simply expose the replication fork to degradation by Exo1. Alternatively, Exo1 may be directly regulated by Rad53. We favor this possibility for several reasons. Firstly, it would help explain specificity. Exol is just one of many Rad2 family 5 '-flap endonucleases (Lieber 1997) and appears to function redundantly with other nucleases in different biological processes. For example, Exol exhibits functional redundancy with $\operatorname{Rad} 27$ (Fen1) in Okazaki fragment processing (Tishkoff et al. 1997; Tran et al. 2002) and with Mre11 for resection of mitotic DSBs (Tsubouchi and Ogawa 2000; Moreau et al. 2001). Yet, we did not find a comparable rad53 suppressor effect by deleting other nucleases (M. Segurado and J.F.X. Diffley, unpubl.). Secondly, the generation of ssDNA at dysfunctional telomeres by Exol has been shown to be negatively regulated by Mec1 and Rad53 (Jia et al. 2004). And finally, quantitative phosphoproteomic approaches in yeast have shown that Exol is phosphorylated in vivo in a Rad53dependent manner in response to MMS treatment (Smolka et al. 2007). We are currently analyzing Rad53dependent phosphorylation of Exo1, and further work is required to determine the effect of that phosphorylation on the regulation of the protein and its influence on the replication forks.

In addition to its role in Rad53 activation, our results indicate that $\mathrm{Mecl}$ has a distinct role in fork stabilization. The sensitivity of mec1s cells to MMS is not suppressed at all by EXO1 deletion. This could be because $\mathrm{Mecl}$ is also required for Chk1 activation; however, mec1 mutants are considerably more sensitive to MMS than rad53chk1 double mutants, indicating that Mec1 has a role not accounted for by Rad53 and Chk1 together. The nature of this role at forks is unclear. ChIP experiments have indicated that checkpoint mutants have defects in maintaining occupancy of replisome components at stalled replication forks (Cobb et al. 2003; Lucca 
et al. 2004; Cotta-Ramusino et al. 2005), although there are conflicting results regarding the contribution of Mec1 and Rad53 kinases to this stabilization. Cotta-Ramusino et al. (2005) have proposed that Rad53 is the critical kinase because rad53 mutants lose DNA polymerases from stalled forks. However, Cobb et al. (2005) have proposed that $\mathrm{Mecl}$ is important to prevent polymerases-replisome disassociation, but that $\operatorname{Rad} 53$ is dispensable. Our results do not resolve this discrepancy. We clearly show genetically separable roles for Mec1 and Rad53 in fork stabilization, at least in MMS. However, our data also demonstrate that rad530 cells show irreversible fork breakdown in HU that is not suppressed by deletion of EXO1. Identification of functionally relevant Mec1, Rad53, and Chk1 substrates will be required for further progress in this area. Recent phosphoproteomic analysis looking for ATR and ATM targets in humans cells in response to DNA damage (Matsuoka et al. 2007) has identified several essential replisome proteins including Mcm2-7 subunits, RFC clamp-loader components, and DNA polymerases. Mcm2-7 proteins are especially interesting candidates because loss of Mcm2-7 from stalled forks causes an irreversible arrest similar to that seen in checkpoint mutants (Labib et al. 2000).

In addition to the roles of Rad53 and Mec1, the fact that the Exo1-dependent suppression in rad53 mutants requires Chk1 implies that this kinase can also regulate replisome stability, at least in the absence of Rad53. This result is surprising due to the fact that $c h k 1$ mutants are relatively insensitive to HU and MMS (Fig. 7A; Sanchez et al. 1999). Our results indicate that, in the absence of Rad53, Chk1 can prevent irreversible DNA replication fork breakdown. Chk1, however, can only accomplish this in the absence of Exo1. This suggests that Rad53 and Chk1 may act redundantly to promote some aspect of replisome stability or replication restart but only Rad53 can counteract the negative effect of Exo1. The fact that

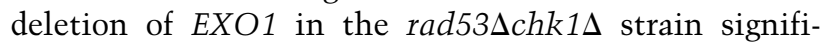
cantly increases sensitivity to MMS suggests that Exol plays a positive role in survival in this background. Clearly, more work is required to determine the role of Chk1 at replication forks.

In Schizosaccharomyces pombe, the Rad53 and Chk1 homologs (Cds1 and Chk1, respectively) (Walworth and Bernards 1996; Lindsay et al. 1998) may have similar overlapping functions. Like Rad53, Cds1 kinase is required for cell survival when replication is inhibited by HU or when DNA is damaged during S phase. Chk1 is activated after DNA damage most commonly during late $S$ and G2 phase. However, when cells are treated with $\mathrm{HU}$ in the absence of Cds1, the checkpoint remains intact and arrest becomes dependent on Chk1 (Martinho et al. 1998; Brondello et al. 1999; O'Connell et al. 2000). Although there may be differences in the functions of the individual checkpoint proteins kinases in different organisms (Rhind and Russell 2000), it is possible that this redundancy may represent a conserved backup system for the Rad53 checkpoint. Regardless, this is the first time that Chk1 has been shown to have a role in the stabilization of replication forks in budding yeast.
Exol homologs have been identified in other eukaryotes, including yeast, flies, and mammalian cells (Szankasi and Smith 1992, 1995; Digilio et al. 1996; Fiorentini et al. 1997; Tishkoff et al. 1998). Further work will be required to determine if the deleterious effect of Exol on replication fork stability and cell viability has been conserved in evolution.

\section{Materials and methods}

Strains, plasmids, and media

All strains used are listed in Supplemental Table S1 and are derived from W303-1a (MATa ade2-1 ura3-1 his3-11, 15 trp1-1 leu2-3, 112 can1-100).

pRS304-EXO1 was created as follows. The EXO1 3-kb genomic fragment was amplified by PCR using Phusion DNA polymerase with the oligos 5'-CAACATCACAGTTCATTGC-3' and 5'-GTTGATAGCGAATGTAGACC-3', and cloned into pRS304 vector. The exo1-D173A allele from YIp-exo1-D173A (Tran et al. 2002) was used to replace the wild-type SpeI-BamHI fragment of pRS304-EXO1 to create pRS304-exo1-D173A. pRS304-exo1-E150D was created by replacing the SpeI-BamHI fragment of pRS304-EXO1with the exo1-E150D allele from YIp-exol-D173A (Tran et al. 2002). The three constructs were sequenced with the oligo EXO1-752.S (5'-GAACCGTATTTGG TCTTCGATG-3') (Tran et al. 2002), to verify correct substitution of the selected fragments. The exo1-point mutant strains were created by targeting MfeI-digested constructs pRS304exo1-D173A and pRS304-exo1-E150D into the TRP locus of a rad $53 \Delta$ exo1s strain.

Unless otherwise indicated, cells were grown at $30^{\circ} \mathrm{C}$ in YP medium (1\% yeast extract [Difco], $2 \%$ bacto peptone [Difco]) supplemented with $2 \%$ glucose (YPD).

\section{Drop assays and viability}

Drop assays were a 1:5 dilution series of exponentially growing cultures on YPD, YPD + MMS, or YPD + HU plates depending on the experiment. In the panels shown in the second and third rows of Figure 2, cells were spotted onto YPD plates and irradiated with ultraviolet or ionizing radiation, respectively, at the indicated dosages.

The viability of asynchronous cultures was calculated by plating $10^{3}$ cells for wild-type and $10^{5}$ cells for checkpoint mutants in duplicate onto YPD $+0.015 \%$ MMS plates (Fig. 1C) or YPD + 0.008\% MMS (Fig. 6B) and scoring after $3 \mathrm{~d}$ at $30^{\circ} \mathrm{C}$.

The viability of synchronous cultures was calculated by plating $10^{3}$ cells for wild-type and $10^{4}$ cells for checkpoint mutants in duplicate onto YPD plates and scoring after $3 \mathrm{~d}$ at $30^{\circ} \mathrm{C}$.

\section{Cell cycle synchronization and flow cytometry}

Cell growth and cell cycle blocks with $\alpha$-factor, HU, and nocodazole were as described previously (Diffley et al. 1994; Donovan et al. 1997). Samples for flow-cytometric analysis (FACS) were collected and processed as described previously (Labib et al. 1999).

\section{DNA replication analysis assays}

Density transfer were performed essentially as described (Tercero et al. 2000). DNA was digested with ClaI and SalI before gradient centrifugation in cesium chloride. DNA probes for slot blot hybridization were amplified by polymerase chain reaction 
(PCR). Probes corresponding to the six fragments were as follows: probe 1 (ARS607), nucleotides 198,945 $\pm 199,832$; probe $2(+10 \mathrm{~kb})$, nucleotides $211,014 \pm 211,996$; probe 3 $(+20 \mathrm{~kb})$, nucleotides $218,011 \pm 218,700$; probe $4(+40 \mathrm{~kb})$, nucleotides $240,009 \pm 240,679$; probe $5(+50 \mathrm{~kb})$, nucleotides $243,315 \pm 244,200$; and probe $6(+65 \mathrm{~kb})$, nucleotides $260,048 \pm 261,088$. The slots blots were probed with these different fragments, and a Molecular Dynamics PhosphorImager was used to detect the hybridization signals.

The analysis of the data was performed basically as described in http://fangman-brewer.genetics.washington.edu/ density_transfer.html with small differences. Briefly, the hybridization signals were quantified and plotted for each time point by using Image Quant TL software. The resulting graphs are shown in Figures 4, 6, and 7 for the indicated strains. For the calculation of the replication fork breakdown rates shown in Figures $4 \mathrm{E}, 6 \mathrm{E}$, and $7 \mathrm{E}$, the areas of the $\mathrm{HH}$ and $\mathrm{HL}$ peaks from each graph at the 240-min time point were measured and quantified with the ImageJ software. The percentage of unreplicated DNA at each position was calculated using the equation:

$$
\% \text { Unreplicated DNA }=[H H / H H+1 / 2 H L] \times 100
$$

This equation takes into account the fact that the HL peak is overrepresented due to the nature of semiconservative DNA replication and so the values obtained from the HL peak should be divided by half to calculate the total signal obtained from replicated plus unreplicated DNA.

Pulse-chase BrdU experiments and immunodetection of BrdU-labeled DNA were performed as described (Vernis et al. 2003).

\section{Acknowledgments}

We are grateful to Michael Liskay for plasmids and advice regarding Exol mutants. We are also grateful to members of the Diffley laboratory for helpful discussions. This work was supported by Cancer Research UK and by EU contract number HPRN-CT-2002-00238.

\section{References}

Allen, J.B., Zhou, Z., Siede, W., Friedberg, E.C., and Elledge, S.J. 1994. The SAD1/RAD53 protein kinase controls multiple checkpoints and DNA damage-induced transcription in yeast. Genes \& Dev. 8: 2401-2415.

Andreassen, P.R., Ho, G.P., and D'Andrea, A.D. 2006. DNA damage responses and their many interactions with the replication fork. Carcinogenesis 27: 883-892.

Bjergbaek, L., Cobb, J.A., Tsai-Pflugfelder, M., and Gasser, S.M. 2005. Mechanistically distinct roles for Sgs1p in checkpoint activation and replication fork maintenance. $E M B O$ J. 24: 405-417.

Branzei, D. and Foiani, M. 2006. The Rad53 signal transduction pathway: Replication fork stabilization, DNA repair, and adaptation. Exp. Cell Res. 312: 2654-2659.

Brondello, J.M., Boddy, M.N., Furnari, B., and Russell, P. 1999. Basis for the checkpoint signal specificity that regulates Chk1 and Cds1 protein kinases. Mol. Cell. Biol. 19: 42624269.

Chan, C.S. and Tye, B.K. 1983. Organization of DNA sequences and replication origins at yeast telomeres. Cell 33: 563-573.

Cobb, J.A., Bjergbaek, L., Shimada, K., Frei, C., and Gasser, S.M. 2003. DNA polymerase stabilization at stalled replication forks requires Mec1 and the RecQ helicase Sgs1. EMBO J. 22:
$4325-4336$.

Cobb, J.A., Schleker, T., Rojas, V., Bjergbaek, L., Tercero, J.A., and Gasser, S.M. 2005. Replisome instability, fork collapse, and gross chromosomal rearrangements arise synergistically from Mecl kinase and RecQ helicase mutations. Genes \& Dev. 19: 3055-3069.

Cotta-Ramusino, C., Fachinetti, D., Lucca, C., Doksani, Y., Lopes, M., Sogo, J., and Foiani, M. 2005. Exol processes stalled replication forks and counteracts fork reversal in checkpoint-defective cells. Mol. Cell 17: 153-159.

Desany, B.A., Alcasabas, A.A., Bachant, J.B., and Elledge, S.J. 1998. Recovery from DNA replicational stress is the essential function of the S-phase checkpoint pathway. Genes \& Dev. 12: 2956-2970.

Diffley, J.F., Cocker, J.H., Dowell, S.J., and Rowley, A. 1994. Two steps in the assembly of complexes at yeast replication origins in vivo. Cell 78: 303-316.

Digilio, F.A., Pannuti, A., Lucchesi, J.C., Furia, M., and Polito, L.C. 1996. Tosca: A Drosophila gene encoding a nuclease specifically expressed in the female germline. Dev. Biol. 178: 90-100.

Donovan, S., Harwood, J., Drury, L.S., and Diffley, J.F. 1997. Cdc6p-dependent loading of Mcm proteins onto pre-replicative chromatin in budding yeast. Proc. Natl. Acad. Sci. 94: $5611-5616$.

Feng, W., Collingwood, D., Boeck, M.E., Fox, L.A., Alvino, G.M., Fangman, W.L., Raghuraman, M.K., and Brewer, B.J. 2006. Genomic mapping of single-stranded DNA in hydroxyurea-challenged yeasts identifies origins of replication. Nat. Cell Biol. 8: 148-155.

Fiorentini, P., Huang, K.N., Tishkoff, D.X., Kolodner, R.D., and Symington, L.S. 1997. Exonuclease I of Saccharomyces cerevisiae functions in mitotic recombination in vivo and in vitro. Mol. Cell. Biol. 17: 2764-2773.

Foiani, M., Pellicioli, A., Lopes, M., Lucca, C., Ferrari, M., Liberi, G., Muzi Falconi, M., and Plevani, P. 2000. DNA damage checkpoints and DNA replication controls in Saccharomyces cerevisiae. Mutat. Res. 451: 187-196.

Friedman, K.L., Brewer, B.J., and Fangman, W.L. 1997. Replication profile of Saccharomyces cerevisiae chromosome VI. Genes Cells 2: 667-678.

Gardner, R., Putnam, C.W., and Weinert, T. 1999. RAD53, DUN1 and PDS1 define two parallel G2/M checkpoint pathways in budding yeast. EMBO I. 18: 3173-3185.

Hartwell, L.H. and Kastan, M.B. 1994. Cell cycle control and cancer. Science 266: 1821-1828.

Jia, X., Weinert, T., and Lydall, D. 2004. Mec1 and Rad53 inhibit formation of single-stranded DNA at telomeres of Saccharomyces cerevisiae cdc13-1 mutants. Genetics 166: 753-764.

Kolodner, R.D., Putnam, C.D., and Myung, K. 2002. Maintenance of genome stability in Saccharomyces cerevisiae. Science 297: 552-557.

Labib, K., Diffley, J.F., and Kearsey, S.E. 1999. G1-phase and B-type cyclins exclude the DNA-replication factor Mcm4 from the nucleus. Nat. Cell Biol. 1: 415-422.

Labib, K., Tercero, J.A., and Diffley, J.F. 2000. Uninterrupted MCM2-7 function required for DNA replication fork progression. Science 288: 1643-1647.

Lieber, M.R. 1997. The FEN-1 family of structure-specific nucleases in eukaryotic DNA replication, recombination and repair. Bioessays 19: 233-240.

Lindsay, H.D., Griffiths, D.J., Edwards, R.J., Christensen, P.U., Murray, J.M., Osman, F., Walworth, N., and Carr, A.M. 1998. S-phase-specific activation of Cds1 kinase defines a subpathway of the checkpoint response in Schizosaccharomyces pombe. Genes \& Dev. 12: 382-395. 
Liu, Y., Vidanes, G., Lin, Y.C., Mori, S., and Siede, W. 2000. Characterization of a Saccharomyces cerevisiae homologue of Schizosaccharomyces pombe Chk1 involved in DNAdamage-induced M-phase arrest. Mol. Gen. Genet. 262: 1132-1146.

Lopes, M., Cotta-Ramusino, C., Pellicioli, A., Liberi, G., Plevani, P., Muzi-Falconi, M., Newlon, C.S., and Foiani, M. 2001. The DNA replication checkpoint response stabilizes stalled replication forks. Nature 412: 557-561.

Lowndes, N.F. and Murguia, J.R. 2000. Sensing and responding to DNA damage. Curr. Opin. Genet. Dev. 10: 17-25.

Lucca, C., Vanoli, F., Cotta-Ramusino, C., Pellicioli, A., Liberi, G., Haber, J., and Foiani, M. 2004. Checkpoint-mediated control of replisome-fork association and signalling in response to replication pausing. Oncogene 23: 1206-1213.

Martinho, R.G., Lindsay, H.D., Flaggs, G., DeMaggio, A.J., Hoekstra, M.F., Carr, A.M., and Bentley, N.J. 1998. Analysis of Rad3 and Chk1 protein kinases defines different checkpoint responses. EMBO J. 17: 7239-7249.

Matsuoka, S., Ballif, B.A., Smogorzewska, A., McDonald III, E.R., Hurov, K.E., Luo, J., Bakalarski, C.E., Zhao, Z., Solimini, N., Lerenthal, Y., et al. 2007. ATM and ATR substrate analysis reveals extensive protein networks responsive to DNA damage. Science 316: 1160-1166.

Moreau, S., Morgan, E.A., and Symington, L.S. 2001. Overlapping functions of the Saccharomyces cerevisiae Mre11, Exo1 and Rad27 nucleases in DNA metabolism. Genetics 159: 1423-1433.

Nyberg, K.A., Michelson, R.J., Putnam, C.W., and Weinert, T.A. 2002. Toward maintaining the genome: DNA damage and replication checkpoints. Annu. Rev. Genet. 36: 617-656.

O'Connell, M.J., Walworth, N.C., and Carr, A.M. 2000. The G2-phase DNA-damage checkpoint. Trends Cell Biol. 10: 296-303.

Paulovich, A.G. and Hartwell, L.H. 1995. A checkpoint regulates the rate of progression through $\mathrm{S}$ phase in $S$. cerevisiae in response to DNA damage. Cell 82: 841-847.

Reynolds, A.E., McCarroll, R.M., Newlon, C.S., and Fangman, W.L. 1989. Time of replication of ARS elements along yeast chromosome III. Mol. Cell. Biol. 9: 4488-4494.

Rhind, N. and Russell, P. 2000. Chk1 and Cds1: Linchpins of the DNA damage and replication checkpoint pathways. J. Cell Sci. 113: 3889-3896.

Sanchez, Y., Bachant, J., Wang, H., Hu, F., Liu, D., Tetzlaff, M., and Elledge, S.J. 1999. Control of the DNA damage checkpoint by chk1 and rad53 protein kinases through distinct mechanisms. Science 286: 1166-1171.

Santocanale, C. and Diffley, J.F. 1998. A Mec1- and Rad53-dependent checkpoint controls late-firing origins of DNA replication. Nature 395: 615-618.

Shirahige, K., Hori, Y., Shiraishi, K., Yamashita, M., Takahashi, K., Obuse, C., Tsurimoto, T., and Yoshikawa, H. 1998. Regulation of DNA-replication origins during cell-cycle progression. Nature 395: 618-621.

Smolka, M.B., Albuquerque, C.P., Chen, S.H., and Zhou, H. 2007. Proteome-wide identification of in vivo targets of DNA damage checkpoint kinases. Proc. Natl. Acad. Sci. 104: 10364-10369.

Sogo, J.M., Lopes, M., and Foiani, M. 2002. Fork reversal and ssDNA accumulation at stalled replication forks owing to checkpoint defects. Science 297: 599-602.

Szankasi, P. and Smith, G.R. 1992. A single-stranded DNA exonuclease from Schizosaccharomyces pombe. Biochemistry 31: 6769-6773.

Szankasi, P. and Smith, G.R. 1995. A role for exonuclease I from $S$. pombe in mutation avoidance and mismatch correction.
Science 267: 1166-1169.

Tercero, J.A. and Diffley, J.F. 2001. Regulation of DNA replication fork progression through damaged DNA by the Mec1/ Rad53 checkpoint. Nature 412: 553-557.

Tercero, J.A., Labib, K., and Diffley, J.F. 2000. DNA synthesis at individual replication forks requires the essential initiation factor Cdc45p. EMBO J. 19: 2082-2093.

Tercero, J.A., Longhese, M.P., and Diffley, J.F. 2003. A central role for DNA replication forks in checkpoint activation and response. Mol. Cell 11: 1323-1336.

Tishkoff, D.X., Boerger, A.L., Bertrand, P., Filosi, N., Gaida, G.M., Kane, M.F., and Kolodner, R.D. 1997. Identification and characterization of Saccharomyces cerevisiae EXO1, a gene encoding an exonuclease that interacts with MSH2. Proc. Nat1. Acad. Sci. 94: 7487-7492.

Tishkoff, D.X., Amin, N.S., Viars, C.S., Arden, K.C., and Kolodner, R.D. 1998. Identification of a human gene encoding a homologue of Saccharomyces cerevisiae EXO1, an exonuclease implicated in mismatch repair and recombination. Cancer Res. 58: 5027-5031.

Tran, P.T., Erdeniz, N., Dudley, S., and Liskay, R.M. 2002. Characterization of nuclease-dependent functions of Exolp in Saccharomyces cerevisiae. DNA Repair (Amst.) 1: 895-912.

Tsubouchi, H. and Ogawa, H. 2000. Exol roles for repair of DNA double-strand breaks and meiotic crossing over in Saccharomyces cerevisiae. Mol. Biol. Cell 11: 2221-2233.

Vernis, L., Piskur, J., and Diffley, J.F. 2003. Reconstitution of an efficient thymidine salvage pathway in Saccharomyces cerevisiae. Nucleic Acids Res. 31: e120. doi: 10.1093/nar/ gng121.

Walworth, N.C. and Bernards, R. 1996. rad-dependent response of the chk1-encoded protein kinase at the DNA damage checkpoint. Science 271: 353-356.

Yamamoto, A., Guacci, V., and Koshland, D. 1996. Pds1p is required for faithful execution of anaphase in the yeast, Saccharomyces cerevisiae. J. Cell Biol. 133: 85-97.

Yamashita, M., Hori, Y., Shinomiya, T., Obuse, C., Tsurimoto, T., Yoshikawa, H., and Shirahige, K. 1997. The efficiency and timing of initiation of replication of multiple replicons of Saccharomyces cerevisiae chromosome VI. Genes Cells 2: 655-665.

Zhou, B.B. and Elledge, S.J. 2000. The DNA damage response: Putting checkpoints in perspective. Nature 408: 433-439. 


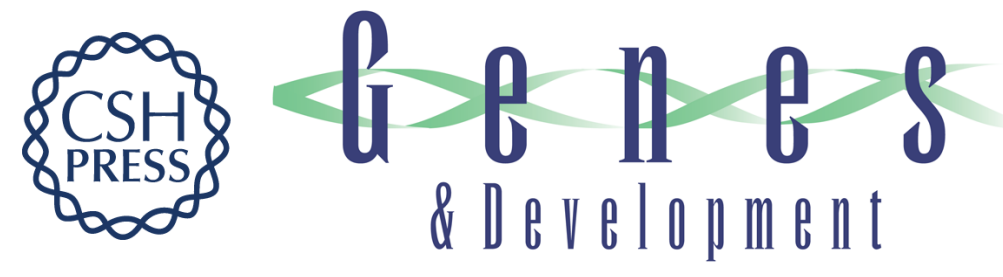

\section{Separate roles for the DNA damage checkpoint protein kinases in stabilizing DNA replication forks}

Monica Segurado and John F.X. Diffley

Genes Dev. 2008, 22:

Access the most recent version at doi:10.1101/gad.477208

Supplemental http://genesdev.cshlp.org/content/suppl/2008/07/01/22.13.1816.DC1
Material

References This article cites 56 articles, 29 of which can be accessed free at:

http://genesdev.cshlp.org/content/22/13/1816.full.html\#ref-list-1

License Freely available online through the Genes \& Development Open Access option.

Email Alerting Receive free email alerts when new articles cite this article - sign up in the box at the top

Service right corner of the article or click here.

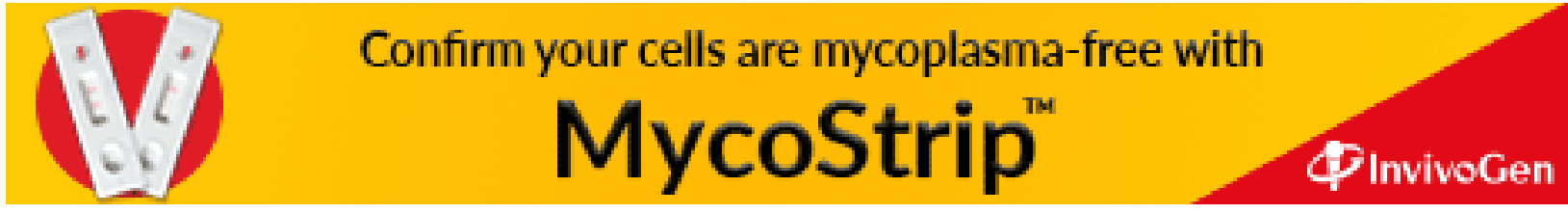

